\title{
Branding an Important Step in Business Success
}

\author{
Behzad Jafari ${ }^{1}$, Forough Behnam Far $^{2}$, Abolfazl Babaei ${ }^{3}$ \& Maryam Faraji ${ }^{4}$ \\ ${ }^{1} \mathrm{PhD}$ student in Business Management International Marketing, International Islamic Azad University, \\ Khorramshahr, Persian Gulf, Iran \\ ${ }^{2}$ Director of Trading Baniyan Bana Khavar Co., Iran \\ ${ }^{3}$ Master of Executive Management, Qeshm International Branch, Islamic Azad University Qeshm Electronic \\ Unit Training Center, Iran \\ ${ }^{4}$ Foreign Purchase Manager, Fanavaran Petrochemical Co., Iran \\ Correspondence: Behzad Jafari, PhD student in Business Management International Marketing, International \\ Islamic Azad University, Khorramshahr, Persian Gulf, Iran. E-mail: Behzadjafari69@jmail.com
}

Received: June 5, 2016

Accepted: July 14, 2016

Online Published: August 15, 2016

doi:10.5539/mas.v10n12p127

URL: http://dx.doi.org/10.5539/mas.v10n12p127

\begin{abstract}
Businesses are always looking for a way to advertise their products and services indirectly, in other words, to stick themselves on their clients and addresses mind. A successful company should try to make familiar their made products years. In this regard whenever the company produces goods and it's attempt is to sell more, then they will advance faster than competitors, if they invent a suitable trade name. Since past creation a trade name has assumed an important proceeding in consumer markets.

Researches show that purchase descions are more complicated in consumer markets, and many companies have set their decisions based on different factors except creation a trade name. Many active companies in trading science ignore creation a trade name and it pursues many risks for them.
\end{abstract}

Keywords: trade name, trade name selection, trade name protection

\section{Introduction}

In market, companies have different marketing ways and strategies to differentiate between their products and competitors.

One of the most important decision is to decide about their brand or trade name selections for their products. If the trade name has been selected based on accurate psychological points, study of consumer behaviors, and correct marketing principles, then it guarantees the success of a product in the market. Suitable brand personality can encourages the person to make a deep relation with that brand personality effects on trust, attachment, and commitment to the brand (Louis \& Lombart, 2010). Trade names face with different challenges during their lifes, when one of the trade names enters in to the market, then it needs to get completely different approaches from old time and wellestablished names in market. Successful and reputed trade names distance generation growth, maturation, candence, and an alternation process and transition to a new generation during their lifes. Frequently, these successful trade names have been experienced new strategic programes by their conscious and expert consultor.

Each trade name is organized into two stractures. The first structure of each trade name is famous for it's evident structure and it is in the domain of advertising company activities. It includes the name, logo, colour, design, and language. Many people focus only on evident part of each trade name when they encounter the structure of the trade name. The second one has been called intangible structure. Infact it is intangible structure of each trade name which is called evident structure that shows how it should be seen. The most important intangible structure of each trade name is it's (identification) that it consists of six dimensions. These identity dimensions include: Personality, figure, culture, self concept, relation, and reflection. Intangible structure codification of each trade name is in the domain of brand consulter groups and institute activities. The beginning step of branding is creation of accurate perception about internal brand identity. Brand is altered to a base and foundation which provide satisfactory framework for the consumers. In this regard the following important points and special service presentations have particular importance because of the existing and new brands. 


\section{Consistently Recognize Your Customers Well}

The starting step of a research is human personality in relation to the brand personality. The concept of brand personality has important managerial advantages which one of them is it's effect on consumer - brand relationships, and it can explains consumer behaviors.

Therefore, this concept can be a new overlook on brand management and performance in the domain of relational marketing (Louis \& Lombart, 2010). World wide brand should be concentrated on advertising attempts so they will not be changed overtime. In cultural dimension, brand personality dimensions consist of friendly, appealling, creative, and complicated in U.S.A, and it commonly exist in Japanese cultures (Aaker, 1996). However, since the peace of brand personality it was specially related to Japanese culture and then the seriousness of brand personality is unique to American culture (Bibby, 2010). Trade name of a production, should be commensurate with the consumer expectations. At the beginning to find a suitable trade name, we should investigate on our consumers well and recognize their requirements. Trade name features are not all always obvious and evident. A good starting point is to research on clients. What is important for your consumers, when they purchase your productions? Compare their requirements with your company and production proceeding. Also look at to your competitors and consider your competitor strengths. Consumer adopt those companies which their attempts are continuous success, so they are looking for developing of those features which have so importance for your consumers.

In consumer markets, companies carry out different researches to control consumer perception changes. This research shows whether your consnmers acquire more favorable opinion on your company or not. Also, it can increase your future sales.

\section{Domain of Your Trade Name Should Be Extensive.}

Your trade name will be applicable to all of your spectrum, if you offer different production and service spectrums. It helps you to manage your business well and to achieve more allegiance of your consumers. Infact, trade name is assumed to be the most valuable asset of the company which it adds value to the final product. Trade name is a scheme of company activities, which it causes consumer -company relationships. In today competitive world, the speed of new competitor enterings to market and providing different services are so fast, so it is important to preserve current consumers. For this purpose, it is so important to have a deep relationship with consumers which we can aim it with our trade name. Trade names can get similar personality human features and it's obvious that each trade name has a presonality. Suitable brand personality can encourage the person to a deep relationship with the brand.

\section{Protect Your Created Trade Name Extremely}

More often, concealed value of a trade name is related to understanding of a practical concept which absorbs the consumers. For example prevenience from heart attacks can cause purshasing medicine. This perception presents the meaning and concept of a production for a consumer. Company can creat much perceptions about it's own brand. Although it is not necessary to exist all possible intentions about a trade name, but It's necessary to exist those perceptions which affect on consumer purchasing behaviours both directly and indirectly (Mir, MirAhamd, Abbasian, \& Farzane, 2007). Reputation is not achieved over night and it will not be last over night. When you make a trade name, and your aim is to open it's place in the market, you should look after this trade name so your cansumer's mind don't be affected by wrong proceedings. The quality of a distinctive factor is important. The Japanese companies are trying to innovate their trade name value, with important developing in quality. Those companies achieve consumer trust which invest on quality. Consumers feel better with a responsible company. This meanes suitable financial performance, powerful management, good industrial background, and effecting production represent background.

\section{Expand Your Relation with Consumers}

Hess and Story have investigate on multidimensional and brand-consumer relationships according to trustbased commitment, and they find that satification of a brand is related to background features but it's more related to functioning dimension of the brand. All personal relationships are trust based between persons and personsbrand. Trust is a bridge between satisfication and personal relations which leads to a close personal relations with the brand (Hess \& Story, 2005).

The importance of brand personality is obvious specially trust to a brand. Many studies have been investigated on trust backgrounds or the effect of trust on an intermediate variable in exchanging systems. In addition, the other issues were investigated carefully so to consider the definition of trust on consumer, seller, purchaser and organization relationships and on purchaser behaviors', trust roles, member distributions, the derive to maintain a 
relation, relational marketing, and industrial - social exchanges. Widespread studies have been done on brand trust, but the processes show decreasing on indicators related with trust.

Trust decreasing includes trust to companies which provide branding goods, business - trust, business leader's trust, and particular industries (Lantieri \& Chiagouris, 2009).

Chudhary \& Holbrocke (2001) believe that the role of brand trust is not investigated clearly among objectors of brand value. Yet related importance is affirmed in prevalent manners or brand management. The aim of the present research is is to fill the distances through invitation of brand - trust importance, and forming dependency. dependency formation process continues through out life. People are depended on their friends, pets, places, and things (Nader, 2009).

One of the most important way of trade name retention and its development is the more relationships with consumers.

It should not done only with advertising but also your production should be in exposed to your consumers, and you should try to preserve the consumers who have tendency to your services and productions. At last it is all of these consumers which forms your product market. Training the consumers help to effective usage of a production. Many companies have training packages and units which guarantee consumers, and personnels to become familiar with new production.

Customized productions are above usual and standard production. Some consumers have individual demands which standard production can't provide them. You can supply these consumer's demands with a high performance by modification of some products. Consultation can convert a company from a production disposure to a valued sharer. Consultation before sale is important because of high cost and complicated productions, and the quality of consultation can assign how to process orders. Technical supports include a spectrum of consultation about product application of after sales services. In complicated products, technical support qualities can be a distinctive element.

\section{Attend Adequately to Environment}

Nowadays people and consumers focus on environment all around the world because of it's serious problems. So in selecting the trade name of your products and company services, use title which shows your attention to environment. Products should be coincident with environment provision because companies are investigated according to their product effects on environment. Use substances which are recoverable. If the company has a role in pollution, then it will have a bad view.

\section{Present Your Customer Lists.}

In developing of a trade name, people trust to each other easily, and they try to examine what the others accept. Some purchasers don't propend to purchase new products which are not affirmed yet. They imperatively don't like these kinds of products, but they want to obtain the best present products. It can easily preserve your new customers for a long time by using your products once. Purchasers test a product according to customer opinion who uses that product before. Presenting a customer list can imdicate the product quality and validation sign.

\section{As You Can, Facilitate Your Connect with Production}

Reaching to a product by its trade name shouldn't be hard and you should facilitate communication between consumers and products. Business becomes easy for consumers with easily presenting order ways. Many companies automize their ordering systems till to economize the time in presenting orders for consumers. Some factors like high quality leaflet, general information via internet, and clear explanation presenting help the purchaser to decide consciously. Brand personality is emotional aspect of brand image on the individual mind. It forms from all experiences which a consumer have from a brand. Advertisement has an effective role in forming a brand personality. Finally a successful brand has opportunity to get leadership position. It is as a dominant exciter of a product in advertising. Firm and wellset position of a brand formed with high range of selling. This message should be presented in all marketing activities (Bahari, 2012).

\section{Do Not Rely More on Advertising}

Some fundamental concepts help us to justify consumer assessing process. From consumers point of view, a product has a set of features. Consumers are different based on their features and what they notice. Consumers differently emphasize on a product based on their individual's demands. The product image is a set of beliefs, which people have about a product by a special sign and trade name. Beliefs and theories affect on purchaser's behaviors'. Theories have descriptive aspects which assign individual's appetency to a matter and belief partly.

Name and trading sign images (product images) are different from trading sign and name and trade sign. Infact 
name and sign trade are as names, phrases, idioms, signs, symbols, designs, models, or a combination of these with the aim of identifying them from competitor's products (Qaedi, et al., 2007).

Some times, companies use advertising for a new trade name creation excessively, like they frequently repeat their trade name in newspapers billboards, and telecasts. Company managers should notice that it can't be succeed just by this way. From the past, trade name creations have been an action in consumer marketing. Studies show that purchasing decisions are more complicated in business market and many companies set their making decision based on different factors expect trade name creation. Many companies acting in business area, ignore creation of trade name, then it follows many risks on Marketing communication which is focused on production and it may fail in powerful point indications of trade name. From consumer's point of view, it can use from company leaflet, and advertisement for a more balanced image of company.

\section{Trade Name Should Be Selected Correctly}

Brand personality has positive and meaningful relationship with consumer trust. Along with, it was suggested to researchers more on brand personality features, and they try to amplify those brand features which attract consumer's trust (Qafari, Peiman, \& Mir, 2011). One of those features which have effect on consumers is an important particle of a product. It's important to consider the image of a trade name on consumers and their understanding (Amir, Mir, Abbasian, \& Farzane, 2007).

Maybe the more manifest skill of a professional member is that $\mathrm{s} / \mathrm{he}$ can create a name and sign of trade, trade name and sign consist name, phrase, idiom, sign, symbol, or design, and a combination of them which is for identifying products and seller services. Trading sign and name have a considerable importance which nowadays it can't be find a product without name and trading sign. In market, trade name and trade sign have different power and worth. A powerful trade name causes to consumers have cling to the products. So trade name has an important role. As for trade name has authority, company can increase the amount of their products. Trade name should pronounce easily. Concise names are more beneficial like Taid or Vanish. Trade name should be identical like oxine. Trade name should be translated easily into a foreign language and it can be recorded. If a product which presents with the name at shop, has a high quality then it will cause to increase consumer trust to this kind of product, so it should be selected carefully. A good name can guarantee the product success.

\section{Conclusion}

Brand has an important role on development and retention of business performance. According to high level of competiton in market, a powerful brand helps the company to contradistinguish itself in the market and it says why it's products and services have the ability to satisfy their consumer demands. Brand is the principal of many businesses and naturally every brand has a personality. We conclude that trade name designer should consider the important features for selecting and protecting from it. Those features are consumer's recognition, trade name spread, trade name protection, spread brand - consumer relationships, brand attention to environment, publishing lists of product brand consumer, and exact brand trade name selection. The aim of branding a product, service or organization is to make a lookout from their trade for consumers. Branding is using of chances for that why people select one brand among the others.

\section{References}

Aaker, D. (1996). Building strong brands, NewYork: The free press.

Amir, S., Mir, A., \& Abbasian, F. (2007). The effect of consumer perceptions of trade name on their reaction. The research: Mobile consumers in Tehran. Humanities and social sciences management, seventh years, (25).

Bahari, Z. (2012). Iran Electronic. Publication of National and Standards Organization (NO. 278).

Bibby, D. N. (2010). Sponstship portfolio as brand image creation strangles: A commentary essay. Journal of Business Research.

Hess, J., \& Story, J. (2005). Trust-bused commitment: multidimensional consumer-brand relationships. Journal of Consumer Marketing, 2216, 313-322.

Lantieri, T., \& Chiagouris, L. (2009). Brand trust in an age with out trust: Expert opinions. Journal of Consumer Marketing, 26(2), 78-86.

Louis, D., \& Lombart, C. (2010). Impact of brand personality on three major relational consequences (trust, attachment, and commitment to the brand). Journal of Product \& Brand Management.

Nader, N. H. (2009). The importance of trust on the brand with its special value (MBA thesis marketing trend). 
Islamic Azad University, Science and Research Branch, Tehran.

Qaedi, M., Mousavi, S. A. R., \& Anvari, A. R. (2007). Consumer product image and beliefs. Journal of Tadbir, (180), 1 .

Qafri, A., P., \& Mir, S. (2011). The effect of brand personality on it's related consequences trust, attachment, commitment. Journal of Pars Modir, (1).

\section{Copyrights}

Copyright for this article is retained by the author(s), with first publication rights granted to the journal.

This is an open-access article distributed under the terms and conditions of the Creative Commons Attribution license (http://creativecommons.org/licenses/by/4.0/). 